\title{
Correlações entre Componentes Anatômicos, Químicos e Digestibilidade In Vitro da Matéria Seca de Gramíneas Forrageiras ${ }^{1}$
}

\author{
Domingos Sávio Campos Paciullo², José Alberto Gomide ${ }^{3}$, Domingos Sávio Queiroz ${ }^{4}$, \\ Eldo Antônio Monteiro da Silva ${ }^{5}$
}

\begin{abstract}
RESUMO - Lâminas foliares e segmentos de colmo das gramíneas forrageiras capim-braquiária (Brachiaria decumbens), capimgordura (Melinis minutiflora) e capim-bermuda Tifton 85 (Cynodon sp) foram amostradas em dois níveis de inserção no perfilho (inferior e superior), em duas idades (momento da exposição da lígula da folha e 20 dias após) e em duas estações de crescimento (verão e outono). Amostras dos segmentos de colmo e lâminas foliares foram submetidas à determinação de sua composição química, composição anatômica e digestibilidade in vitro. Após obtenção dos dados, foram estabelecidas as correlações entre os componentes químicos e anatômicos e entre estes e a DIVMS, na lâmina, no colmo e no agrupamento dos dados das duas frações. A espessura da parede celular foi a característica anatômica a se correlacionar mais fortemente com todos os componentes químicos, independente da fração considerada. Suas correlações foram positivas com os teores de fibra em detergente neutro, fibra em detergente ácido e lignina e negativa com os de proteína bruta. A proporção de mesofilo se correlacionou positivamente com os teores de proteína bruta e negativamente com os de fibra em detergente ácido, enquanto a proporção de esclerênquima apresentou correlação positiva com os teores de fibra em detergente neutro. Os componentes químicos se correlacionaram fortemente entre si e com a DIVMS. Entre as características anatômicas, somente a espessura da parede celular mostrou correlação significativa com a DIVMS, independente da fração. O mesofilo se correlacionou positivamente e o xilema negativamente com a DIVMS, respectivamente, na lâmina e no colmo.
\end{abstract}

Palavras-chave: Brachiaria decumbens, Cynodon sp, digestibilidade in vitro da matéria seca, espessura da parede celular, Melinis minutiflora, proporção de tecidos

\section{Chemical and Anatomical Traits, and in Vitro Dry Matter Digestibility Correlations in Forage Grasses}

\begin{abstract}
Leaf blades and stem segments at two stages of development (day of leaf ligule exposure and 20 days thereafter) and two insertion levels on tillers (lower and upper) of signalgrass (Brachiaria decumbens), molassesgrass (Melinis minutiflora) and tifton 85 bermudagrass (Cynodon sp), were sampled in two seasons of the year (summer and autumn). The anatomical and chemical traits, and in vitro dry matter digestibility of blades and stems segments were evaluated. The correlations among these variables were established to associated values observed in leaf blade and stem, and to each fraction. The cell wall thickness was the anatomical trait to exhibit the highest correlation with all the chemical components, being positive with neutral detergent fiber, acid detergent fiber and lignin contents and negative with crude protein content. The proportion of mesophyll correlated positively with crude protein and negatively with acid detergent fiber content, while the proportion of sclerenchyma showed positive correlation with neutral detergent fiber content. The chemical components showed strong correlation among themselves and with the IVDMD. From the anatomical traits, the cell wall thickness was the only one to exhibit a significant correlation with the IVDMD, independent of fraction. The IVDMD correlated positively with leaf blade mesophyll and negatively with stem xylem.
\end{abstract}

Key Words: Brachiaria decumbens, cell wall thickness, Cynodon sp, in vitro dry matter digestibility, Melinis minutiflora, tissue proportion

\section{Introdução}

A maioria das gramíneas tropicais possui estrutura foliar conhecida como anatomia tipo Kranz, substancialmente diferente da estrutura anatômica das gramíneas temperadas. A anatomia da folha está relacionada à via fotossintética $\mathrm{C}_{4}$ ou $\mathrm{C}_{3}$, que carac- teriza as gramíneas tropicais e temperadas, respectivamente (LAETSCH, 1974). As principais características que distinguem tais gramíneas são as mais altas proporções de feixes vasculares e de células da bainha parenquimática dos feixes, em gramíneas $\mathrm{C}_{4}$, e a maior quantidade de células do mesofilo entre os feixes vasculares, em gramíneas $\mathrm{C}_{3}$. Estas diferenças

\footnotetext{
1 Parte da tese apresentada pelo primeiro autor à UFV para obtenção do título Doctor Scientiae.

2 Bolsista de Recém-doutor da Embrapa Gado de Leite. E.mail: dscp@terra.com.br

3 Pesquisador IA do CNPq. Departamento de Zootecnia - UFV. Viçosa, MG.

4 Pesquisador da EPAMIG - UFV. Viçosa, MG.

5 Professor do Departamento de Biologia Vegetal - UFV. Viçosa, MG.
} 
na proporção de tecidos podem explicar, em parte, as diferenças de valor nutritivo entre gramíneas tropicais e temperadas (WILSON et al., 1983). Dentro do mesmo grupo fotossintético, diferenças anatômicas entre espécies e/ou cultivares também podem refletir diferenças no valor nutritivo da forragem (WILSON et al., 1983; QUEIROZ et al., 2000b).

Alguns autores têm estabelecido a relação entre anatomia, composição química e digestibilidade de gramíneas forrageiras. Correlações altamente significativas entre a proporção de tecidos individuais, ou em combinação, e as entidades nutricionais têm sido observadas (WILSON et al., 1989; QUEIROZ, 2000b). Em geral, tecidos rápida e totalmente digeridos, como o mesofilo, apresentam correlações positivas com os coeficientes de digestibilidade e os teores de proteína bruta e negativas com os teores de parede celular. Por outro lado, tecidos resistentes à digestão, como o xilema e o esclerênquima, ou de digestão lenta e parcial, como a bainha parenquimática dos feixes, correlacionam-se positivamente com os teores de parede celular e de lignina e negativamente com a digestibilidade.

A estrutura anatômica básica das gramíneas tropicais apresenta limitação adicional à digestibilidade, devido aos elevados teores de parede celular associados à anatomia tipo Kranz (WILSON et al., 1983). Embora nutricionalmente importante, por apresentar frações potencialmente digestíveis, a parede celular, quando em elevadas concentrações na forragem, resulta em comprometimento da digestibilidade $\mathrm{e}$ consumo pelos ruminantes. De acordo com WILSON (1994), a digestibilidade da parede celular ou da fração fibrosa em forrageiras pode variar de 30 a $60 \%$ e, dependendo do tipo de célula, de 0 a $100 \%$. Em geral, os constituintes fibrosos (fibra em detergente neutro, fibra em detergente ácido e lignina) são correlacionados negativamente com a digestibilidade (WILSON et al., 1983; WEISS, 1994; QUEIROZ et al., 2000a).

Correlação dos teores de fibra em detergente neutro e fibra em detergente ácido com a digestibilidade, parece estar condicionada ao grau de associação entre os teores de lignina e de fibra. Se esta associação é baixa, o conteúdo de fibra da forrageira não será bom indicador da digestibilidade (VAN SOEST, 1994; QUEIROZ et al., 2000a).

Os teores de fibra em detergente ácido são, freqüentemente, utilizados para estimativas da digestibilidade (WEISS, 1994). Os coeficientes de correlação entre as concentrações de fibra em deter- gente ácido e a digestibilidade da matéria seca variam entre -0,5 e -0,95 (MINSON, 1982). Leguminosas tendem a apresentar teor de lignina mais elevado que as gramíneas, de mesma digestibilidade. Este fato contribui para o baixo coeficiente de determinação das equações de regressão baseadas nos valores de fibra em detergente ácido usadas, para predizer a digestibilidade de populações mistas de gramíneas e leguminosas (ABRAMS, 1988). Por essa razão, correlações mais altas são obtidas quando gramíneas e leguminosas são avaliadas separadamente, e mais altas ainda em estudos envolvendo poucas espécies de gramíneas.

A lignina é o principal componente químico a limitar a digestibilidade de forrageiras (AKIN e CHESSON, 1989; JUNG e DEETZ, 1993; JUNG e ALLEN, 1995). Altas e negativas correlações têm sido obtidas entre os teores de lignina, determinados por diferentes metodologias, e a digestibilidade in vitro da matéria seca (JUNG et al., 1997; QUEIROZ et al., 2000a). Entretanto, a variação na digestibiidade não pode ser explicada somente pela concentração de lignina. JUNG e ALLEN (1995) relatam que a composição da lignina pode diferir entre espécies, cultivares, frações da planta e tecidos, o que modifica o impacto da lignificação sobre a digestibilidade e explica a ocorrência de baixa correlação entre a concentração de lignina e a digestibilidade da parede celular (HALIM et al., 1989; JUNG e CASLER, 1991; JUNG e VOGEL, 1992), ou ainda a correlação positiva da lignina com a digestibilidade (JUNG et al., 1994). Segundo JUNG e ALLEN (1995), altas correlações negativas têm sido consistentemente encontradas, quando a análise inclui várias espécies de gramíneas, em diferentes estádios de maturidade e, freqüentemente, envolve toda a planta. Por outro lado, os resultados têm sido inconsistentes em avaliações limitadas a uma espécie forrageira em estádios de maturidade semelhantes, ou quando as análises envolvem, conjuntamente, gramíneas e leguminosas.

O objetivo deste trabalho foi avaliar o grau de correlação entre componentes químicos e anatômicos, e entre estes componentes e a digestibilidade in vitro da matéria seca de lâminas foliares e colmos, em três gramíneas forrageiras.

\section{Material e métodos}

Lâminas foliares e segmentos de colmo das gramíneas forrageiras capim-braquiária (Brachiaria decumbens), capim-gordura (Melinis minutiflora) 
Rev. bras. zootec.

e capim-bermuda Tifton 85 (Cynodon $s p$ ) foram avaliados quanto aos efeitos da idade, do nível de inserção no perfilho (só para lâmina foliar) e da estação de crescimento sobre características anatômicas e nutricionais. As gramíneas foram plantadas em novembro de 1996, cada espécie em uma parcela de $20 \mathrm{~m}^{2}$, sendo o experimento iniciado em dezembro de 1998. Após corte de uniformização, realizado com cutelo, à altura de $5 \mathrm{~cm}$ acima do solo, foi feita adubação em cobertura com sulfato de amônio $(60 \mathrm{~kg} / \mathrm{ha}$ de N), cloreto de potássio $(60 \mathrm{~kg} / \mathrm{ha}$ de $\mathrm{K}_{2} \mathrm{O}$ ) e superfosfato simples $\left(80 \mathrm{~kg} / \mathrm{ha}\right.$ de $\left.\mathrm{P}_{2} \mathrm{O}_{5}\right)$.

Foram selecionados e identificados com anéis de mesma coloração quatro grupos de 10 perfilhos em cada parcela. No primeiro grupo de dez perfilhos, coletou-se a $3^{\text {a }}$ folha, da base para o topo, do perfilho de capim-braquiária e capim-gordura e a $4^{\mathrm{a}}$ folha de capim-bermuda Tifton 85 (folhas de nível de inserção inferior), no momento da completa expansão (idade 0 ), caracterizado pelo aparecimento da lígula. No segundo grupo de perfilhos, foram retiradas folhas do nível de inserção inferior, porém 20 dias após o aparecimento da lígula (idade 20). No terceiro grupo de perfilhos, coletaram-se a $7^{\mathrm{a}}$ folha de capim-braquiária e capim-gordura e a $11^{\text {a }}$ de capim-bermuda Tifton 85 (folhas de nível de inserção superior) na idade 0. No quarto grupo de perfilhos, amostraram-se folhas na idade 20 e situadas no nível de inserção superior.

Foi amostrado o segmento de colmo localizado imediatamente abaixo da folha de nível de inserção superior, apenas, tendo em vista que, no momento da colheita da folha de nível de inserção inferior, o colmo não havia sido formado, existindo apenas pseudocolmo.

Foram realizadas avaliações em duas estações de crescimento: nos meses de dezembro/98 e janeiro/99 foram amostrados os perfilhos do crescimento de verão e nos meses de maio e junho de 1999, colheram-se amostras de perfilhos do crescimento de outono.

De cada perfilho, amostraram-se a lâmina e o segmento de colmo pré-determinados. Este material foi levado à estufa para secagem a $60^{\circ} \mathrm{C}$. Depois de secas, as amostras foram moídas em moinho tipo Willey com peneira de $1 \mathrm{~mm}$ de abertura e acondicionadas em vidros para análises posteriores.

Foram analisados os teores de matéria seca (MS) a $105^{\circ} \mathrm{C}$, segundo SILVA (1990); proteína bruta (PB), segundo o método semimicro Kjeldhal, usando fator 6,25 para conversão de nitrogênio em proteína bruta(ASSOCIATIONOFOFICIALAGRICULTURAL CHEMIST - AOAC, 1970); fibra em detergente neutro (FDN), fibra em detergente ácido (FDA) e lignina no resíduo do detergente ácido com uso de permanganato de potássio, segundo Van Soest e Wine (1968), citados por SILVA (1990). Os teores de hemicelulose e celulose foram estimados por diferença. A digestibilidade in vitro da matéria seca (DIVMS) seguiu metodologia de TILLEY e TERRY (1963).

Para as avaliações anatômicas, três segmentos (correspondentes a três repetições de cada tratamento) da lâmina e do colmo foram fixados em FAA, desidratados e incluídos em "paraplast", para seccionamento em micrótomo a $10 \mathrm{~mm}$ e posterior montagem em lâminas permanentes. A mensuração da contribuição de cada tecido para a área total da seção foi feita com uso do software IMAGE-PRO, acoplado a um microscópio binocular. Foram determinadas as áreas do mesofilo, epiderme, bainha parenquimática dos feixes, esclerênquima, xilema, além do parênquima no colmo. Foram medidas as espessuras das paredes de células esclerenquimáticas associadas aos feixes vasculares maiores na lâmina foliar e aquelas do anel esclerenquimático no colmo. As paredes de células dos vasos de metaxilema foram medidas nos feixes vasculares maiores.

Correlações lineares entre todas as características foram estimadas para a lâmina foliar (48 observações), para o colmo (24 observações) e para o agrupamento dos dados das duas frações (72 observações).

Foram obtidas, também, correlações dos componentes anatômicos e químicos com a DIVMS para a lâmina (16 observações), o colmo (8 observações) e as duas frações (24 observações), considerando cada espécie separadamente.

\section{Resultados e Discussão}

Coeficientes de correlação entre componentes químicos e anatômicos da lâmina foliar, do colmo e da lâmina + colmo, considerando o agrupamento dos dados das três espécies, são apresentados nas Tabelas 1, 2, 3 e 4 .

A espessura da parede de células do esclerênquima e do metaxilema na lâmina foliar apresentou associações altamente significativas com todos os componentes químicos, mostrando correlação negativa com os teores de PB e positiva com os componentes da fração fibrosa (FDN, FDA e lignina) (Tabela 1).

O mesofilo, composto por células de parede delgada e normalmente não lignificada, apresentou correlação positiva com os teores de $\mathrm{PB}$ e negativa com os de FDA. Comportamento inverso foi verificado para a proporção de xilema. 
As proporções de esclerênquima e epiderme mostraram estreita correlação $(\mathrm{P}<0,05)$ apenas com os teores de FDN. A lignina foi, em geral, o componente químico de mais baixa correlação com as proporções de tecidos. Assim, com exceção da associação significativa dos teores de lignina com a espessura da parede celular, todas as demais correlações da lignina com os componentes anatômicos foram não significativas. Por outro lado, a lignina se correlacionou fortemente com todos os componentes químicos. As correlações foram positivas com os teores de FDN e FDA e negativa com os de PB.
O número de correlações significativas no colmo (Tabela 2) foi, em geral, menor que na lâmina foliar, embora as correlações significativas tenham apresentado valores mais elevados. A exemplo do que aconteceu na lâmina, a espessura da parede celular do esclerênquima e do metaxilema foi a característica anatômica que melhor se correlacionou com os componentes químicos. Além desses, a proporção de esclerênquima também apresentou correlações significativas com os teores de PB, FDN, FDA e lignina. $\mathrm{O}$ parênquima e a epiderme apresentaram correlações negativas com os teores de FDA $(\mathrm{P}<0,01)$ e

Tabela 1 - Correlações lineares entre componentes químicos e anatômicos em lâminas foliares de gramíneas forrageiras ( $n=48$ observações)

Table 1 - Linear correlations between chemical and anatomical components in leaf blades of forage grasses ( $n=48$ observations)

\begin{tabular}{|c|c|c|c|c|c|c|c|c|c|c|c|}
\hline $\begin{array}{l}\text { Variável }^{1} \\
\text { Variable }^{2}\end{array}$ & MES & $\begin{array}{l}\text { XIL } \\
X Y L\end{array}$ & EPI _ & $\begin{array}{l}\text { ESC } \\
S C L\end{array}$ & $\begin{array}{l}\text { BPF } \\
P B S\end{array}$ & $\begin{array}{l}\text { EPE } \\
S W T\end{array}$ & $\begin{array}{l}\text { EPM } \\
M W T\end{array}$ & $\begin{array}{l}\mathrm{PB} \\
C P\end{array}$ & $\begin{array}{l}\text { FDN } \\
N D F\end{array}$ & $\begin{array}{l}\text { FDA } \\
A D F\end{array}$ & LIG \\
\hline MES & - & $-0,65 * * *$ & 0,18 & $0,41 * *$ & $-0,85 * * *$ & $-0,49 * * *$ & $-0,23 *$ & $0,33 * *$ & 0,23 & $-0,35^{* *}$ & $-0,03$ \\
\hline $\mathrm{XIL}(X Y L)$ & & - & $-0,06$ & 0,17 & $0,36 * *$ & $0,56 * * *$ & $0,28 *$ & $-0,51 * * *$ & 0,09 & $0,31^{*}$ & $-0,11$ \\
\hline EPI & & & - & $0,56 * * *$ & $-0,40 * *$ & 0,10 & 0,06 & $-0,05$ & $0,34 * *$ & 0,03 & $-0,16$ \\
\hline $\mathrm{ESC}(S C L)$ & & & & - & $-0,64 * * *$ & 0,23 & $0,27 *$ & $-0,17$ & $0,65 * * *$ & $-0,05$ & $-0,18$ \\
\hline $\mathrm{BPF}(P B S)$ & & & & & - & $0,35 * *$ & $0,24 *$ & $-0,16$ & $-0,37 * *$ & $0,29 *$ & 0,17 \\
\hline $\mathrm{EPE}(S W T)$ & & & & & - & $0,79 * * *$ & $-0,68 * * *$ & $0,51 * * *$ & $0,51 * * *$ & $0,34 * *$ & \\
\hline $\operatorname{EPM}(M W T)$ & & & & & & & - & $-0,50 * * *$ & $0,47 * * *$ & $0,49 * * *$ & $0,31 * *$ \\
\hline $\mathrm{PB}(C P)$ & & & & & & & & - & $-0,56 * * *$ & $-0,73 * * *$ & $-0,57 * * *$ \\
\hline $\mathrm{FDN}(N D F)$ & & & & & & & & & - & $0,36 * *$ & $0,42 * *$ \\
\hline $\operatorname{FDA}(A D F)$ & & & & & & & & & & - & $0,49 * * *$ \\
\hline
\end{tabular}

LG

${ }^{1}$ MES - mesofilo (mesophyll), XIL (XYL) - xilema (xylem), EPI - epiderme (epidermis), ESC (SCL) - esclerênquima (sclerenchyma), BPF (PBS) - bainha parenquimática dos feixes (parenchyma bundle sheath), EPE (SWT) - espessura da parede de células do esclerênquima (sclerenchyma cell wall thickness), EPM (MWT) - espessura da parede de células do metaxilema (metaxylem cell wall thickness), PB (CP) - proteína bruta (crude protein), FDN (NDF) - fibra em detergente neutro (neutral detergent fiber), FDA (ADF) - fibra em detergente ácido (acid detergent fiber) e LIG - lignina (lignin).

${ }^{*}(P<0,05),{ }^{* *}(P<0,01),{ }^{* * \star}(P<0,001)$.

Tabela 2 - Correlações lineares entre componentes químicos e anatômicos em colmos de gramíneas forrageiras ( $n=24$ observações)

Table 2 - Linear correlations between chemical and anatomical components in stems of forage grasses $(n=24$ observations)

\begin{tabular}{|c|c|c|c|c|c|c|c|c|c|c|}
\hline $\begin{array}{l}\text { Variável }^{1} \\
\text { Variable }^{2}\end{array}$ & EPI & PAR & $\begin{array}{l}\text { XIL } \\
X Y L\end{array}$ & $\begin{array}{l}\text { ESC } \\
S C L \\
\end{array}$ & $\begin{array}{l}\text { EPE } \\
S W T\end{array}$ & $\begin{array}{l}\text { EPM } \\
M W T\end{array}$ & $\begin{array}{l}\mathrm{PB} \\
C P\end{array}$ & $\begin{array}{l}\mathrm{FDN} \\
N D F\end{array}$ & $\begin{array}{l}\text { FDA } \\
A D F\end{array}$ & LIG \\
\hline EPI & - & $-0,10$ & 0,23 & $-0,22$ & $-0,21$ & 0,01 & 0,22 & $-0,41 *$ & $-0,20$ & $-0,25$ \\
\hline PAR & & - & $-0,83 * * *$ & $-0,82 * * *$ & $-0,08$ & $-0,15$ & 0,11 & $-0,03$ & $-0,50 * *$ & $-0,30$ \\
\hline $\mathrm{XIL}(X Y L)$ & & & - & $0,48 * *$ & $-0,21$ & $-0,19$ & 0,10 & $-0,29$ & $0,40^{*}$ & $-0,05$ \\
\hline $\operatorname{ESC}(S C L)$ & & & & - & $0,44 *$ & $0,36^{*}$ & $-0,50 * *$ & $0,51 * *$ & $0,66 * * *$ & $0,65 * * *$ \\
\hline $\operatorname{EPE}(S W T)$ & & & & & - & $0,74 * * *$ & $-0,65 * * *$ & $0,75 * * *$ & $0,52 * *$ & $0,91 * * *$ \\
\hline $\operatorname{EPM}(M W T)$ & & & & & & - & $-0,18$ & $0,44^{*}$ & $0,35^{*}$ & $0,71 * * *$ \\
\hline $\mathrm{PB}(C P)$ & & & & & & & - & $-0,85 * * *$ & $-0,57 * *$ & $-0,69 * * *$ \\
\hline $\operatorname{FDN}(N D F)$ & & & & & & & & - & $0,48 * *$ & $0,80 * * *$ \\
\hline $\operatorname{FDA}(A D F)$ & & & & & & & & & - & $0,62 * * *$ \\
\hline LIG & & & & & & & & & & - \\
\hline
\end{tabular}

1 EPI-epiderme (epidermis), PAR-parenquima (parenchyma), XIL (XYL)-xilema (xylem), ESC (SCL)-esclerênquima (sclerenchyma), EPE (SWT)-espessura da parede de células do esclerênquima (sclerenchyma cell wall thickness), EPM (MWT) - espessura da parede de células do metaxilema (metaxylem cell wall thickness), PB (CP)-proteína bruta (crude protein), FDN (NDF)- fibra em detergente neutro (neutral detergent fiber), FDA (ADF) - fibra em detergente ácido (acid detergent fiber) e LIG - lignina (lignin).

* $(P<0,05),{ }^{* *}(P<0,01),{ }^{* \star *}(P<0,001)$. 
Rev. bras. zootec.

FDN $(\mathrm{P}<0,05)$, respectivamente, enquanto o xilema se associou positivamente com a FDA $(\mathrm{P}<0,05)$.

Repetindo relato de JUNG e ALLEN (1995), acentuada melhoria das correlações entre as características anatômicas e químicas foi observada com o agrupamento dos dados de colmo e lâmina foliar (Tabela 3). Neste estudo, a associação dos dados da lâmina foliar e do colmo aumentou o número de observações e propiciou maiores diferenças entre valores extremos observados para as características anatômicas e químicas. As proporções de xilema e esclerênquima, bem como as espessuras das paredes celulares, se correlacionaram $(\mathrm{P}<0,001)$ negativamente com os teores de PB e positivamente com os de FDN, FDA e lignina. Por outro lado, a epiderme mostrou comportamento inverso.

Todas as características químicas estudadas (PB, FDN, FDA e lignina) apresentaram correlações altamente significativas com a digestibilidade, independente da fração (Tabela 4). Entretanto, apenas a espessura da parede de células do esclerênquima e do metaxilema, entre os componentes anatômicos, mostrou correlação $(\mathrm{P}<0,001)$ com a digestibilidade, independente da fração considerada. Na lâmina foliar, o mesofilo apresentou associação positiva e a bainha parenquimática dos feixes, negativa; no colmo, o xilema correlacionou-se negativamente com a digestibilidade. Embora freqüentemente se correlacione negativamente com a digestibilidade (QUEIROZ et al., 2000b), a proporção de esclerênquima apresentou correlação significativa somente quando se associaram os dados da lâmina e do colmo. Sua contribuição para a área de tecido é pequena, mas a elevada espessura de sua parede celular tem forte impacto negativo na qualidade da forragem (WILSON, 1994).

Equações de regressão entre a DIVMS e os teores de FDN, FDA e lignina e a espessura da parede de células do esclerênquima, característica anatômica mais consistentemente correlacionada com a DIVMS, são apresentadas na Figura 1. O coeficiente de regressão linear foi mais elevado para as características da lâmina foliar que do colmo. Assim, foram encontrados os coeficientes de $-0,55$ e $-0,45 \%$ de digestibilidade/unidade percentual de FDN, $-1,36 \mathrm{e}$ $-0,30 \%$ de digestibilidade/unidade percentual de FDA, $-4,60$ e $-0,68 \%$ de digestibilidade/unidade percentual de lignina e - 10,30 e $-2,64 \%$ de digestibilidade/mm da parede de células do esclerênquima, para a lâmina e o colmo, respectivamente. Estes valores indicam que a DIVMS da lâmina foi mais prejudicada que a do colmo para um mesmo incremento nos teores de FDN, FDA e lignina ou na espessura da parede. Em geral, colmos jovens apresentam elevada digestibilidade, que com a maturidade decresce mais intensamente que em lâminas foliares (NELSON e MOSER, 1994). A discordância entre os resultados encontrados neste estudo e os relatados na literatura pode ser atribuída, provavelmente, ao fato de que os menores teores de FDN (acima de 70\%) e FDA (acima de 45\%) encontrados no colmo parecem já suficientemente elevados para limitarem a DIVMS. Portanto, a digestibilidade dos colmos sofreu pequena queda com a maturidade. Por outro lado, a DIVMS de lâminas foliares, elevada no momento da exposição

Tabela 3 - Correlações lineares entre componentes químicos e anatômicos nos dados associados das lâminas foliares e colmos de gramíneas forrageiras ( $\mathrm{n}=72$ observações)

Table 3 - Linear correlations between chemical and anatomical components from associated values of leaf blade and stems of forage grasses ( $n=72$ observations)

\begin{tabular}{|c|c|c|c|c|c|c|c|c|c|}
\hline $\begin{array}{l}\text { Variável }^{1} \\
\text { Variable }^{2}\end{array}$ & XIL & $\begin{array}{l}\text { EPI } \\
X Y L \\
\end{array}$ & $\begin{array}{l}\text { ESC } \\
S C L \\
\end{array}$ & $\begin{array}{l}\text { EPE } \\
S W T\end{array}$ & $\begin{array}{l}\text { EPM } \\
M W T\end{array}$ & $\begin{array}{l}\text { PB } \\
C P\end{array}$ & $\begin{array}{l}\text { FDN } \\
N D F\end{array}$ & $\begin{array}{l}\text { FDA } \\
A D F\end{array}$ & LIG \\
\hline $\mathrm{XIL}(X Y L)$ & - & $-0,85 * * *$ & $0,86 * * *$ & $-0,01$ & $0,64 * * *$ & $-0,74 * * *$ & $0,70 * * *$ & $0,84 * * *$ & $0,63 * * *$ \\
\hline EPI & & - & $-0,83 * * *$ & $-0,06$ & $-0,75^{* * *} *$ & $0,81 * * *$ & $-0,82 * * *$ & $-0,84 * * *$ & $-0,75 * * *$ \\
\hline $\mathrm{ESC}(S C L)$ & & & - & $0,26^{*}$ & $0,75 * * *$ & $-0,78 * * *$ & $0,85 * * *$ & $0,87 * * *$ & $0,83 * * *$ \\
\hline $\operatorname{EPE}(S W T)$ & & & & - & $0,51 * * *$ & $-0,34 * *$ & $0,35 * *$ & $0,32 * *$ & $0,59 * * *$ \\
\hline $\operatorname{EPM}(M W T)$ & & & & & - & $-0,77 * * *$ & $0,80 * * *$ & $0,79 * * *$ & $0,81 * * *$ \\
\hline $\mathrm{PB}(C P)$ & & & & & & - & $-0,89 * * *$ & $-0,87 * * *$ & $-0,78 * * *$ \\
\hline $\mathrm{FDN}(N D F)$ & & & & & & & - & $0,84 * * *$ & $0,83 * * *$ \\
\hline $\operatorname{FDA}(A D F)$ & & & & & & & & - & $0,84 * * *$ \\
\hline LIG & & & & & & & & & - \\
\hline
\end{tabular}

${ }_{1}^{1}$ XIL (XYL) - xilema (xylem), EPI - epiderme (epidermis), ESC (SCL) - esclerênquima (sclerenchyma), EPE (SWT) - espessura da parede de células do esclerênquima (sclerenchyma cell wall thickness), EPM (MWT) - espessura da parede de células do metaxilema (metaxylem cell wall thickness), PB (CP) - proteína bruta (crude protein), FDN (NDF) - fibra em detergente neutro (neutral detergent fiber), FDA (ADF) - fibra em detergente ácido (acid detergent fiber) e LIG - lignina (lignin).

${ }^{*}(\mathrm{P}<0,05),{ }^{* *}(\mathrm{P}<0,01),{ }^{* * *}(\mathrm{P}<0,001)$. 
Tabela 4 - Correlações lineares entre a DIVMS e os componentes químicos e anatômicos em lâminas foliares, colmos e nos dados associados da lâmina e do colmo de gramíneas forrageiras

Table 4 - Linear correlations between IVDMD and chemical and anatomical components in leaf blades, stems and in associated values of leaf blades and stems of forage grasses

\begin{tabular}{|c|c|c|c|}
\hline \multirow[t]{2}{*}{$\begin{array}{l}\text { Variável } \\
\text { Variable }\end{array}$} & \multicolumn{3}{|c|}{$\begin{array}{l}\text { Fração do perfilho } \\
\text { Tiller fraction }\end{array}$} \\
\hline & $\begin{array}{l}\text { Lâmina foliar } \\
\text { Leaf blade }\end{array}$ & $\begin{array}{l}\text { Colmo } \\
\text { Stem }\end{array}$ & $\begin{array}{l}\text { Lâmina foliar + colmo } \\
\text { Leaf blade }+ \text { stem }\end{array}$ \\
\hline $\begin{array}{l}\text { Mesofilo } \\
\text { Mesophyll }\end{array}$ & $0,43^{*}$ & - & - \\
\hline $\begin{array}{l}\text { Parênquima } \\
\text { Parenchyma }\end{array}$ & - & $-0,02$ & - \\
\hline $\begin{array}{l}\text { Xilema } \\
\text { Xylem }\end{array}$ & 0,23 & $-0,35^{*}$ & $-0,52 * *$ \\
\hline $\begin{array}{l}\text { Bainha parenquimática dos feixes } \\
\text { Parenchyma blundle sheath }\end{array}$ & $-0,34^{*}$ & - & - \\
\hline $\begin{array}{l}\text { Esclerênquima } \\
\text { Sclerenchyma }\end{array}$ & 0,04 & $-0,24$ & $-0,53 * *$ \\
\hline $\begin{array}{l}\text { Espessura da parede esclerênquima } \\
\text { Sclerenchyma cell wall thickness }\end{array}$ & $-0,68 * *$ & $-0,76^{* *}$ & $-0,45 * *$ \\
\hline $\begin{array}{l}\text { Espessura da parede metaxilema } \\
\text { Metaxylem cell wall thickness }\end{array}$ & $-0,58 * *$ & $-0,54 * *$ & $-0,72 * *$ \\
\hline $\begin{array}{l}\text { Proteína bruta } \\
\text { Crude protein }\end{array}$ & $0,70 * *$ & $0,65^{* *}$ & $0,81 * *$ \\
\hline $\begin{array}{l}\text { Fibra em detergente neutro } \\
\text { Neutral detergent fiber }\end{array}$ & $-0,36^{*}$ & $-0,66^{* *}$ & $-0,68 * *$ \\
\hline $\begin{array}{l}\text { Fibra em detergente ácido } \\
\text { Acid detergent fiber }\end{array}$ & $-0,68^{* *}$ & $-0,58 * *$ & $-0,73 * *$ \\
\hline $\begin{array}{l}\text { Lignina } \\
\text { Lignin }\end{array}$ & $-0,59^{* *}$ & $-0,70 * *$ & $-0,67 * *$ \\
\hline
\end{tabular}

da lígula, decresceu acentuadamente em resposta a incrementos nas concentrações de fibra.

Além do estudo de correlações com os dados agrupados das três espécies, relatado anteriormente, foram verificadas as correlações entre a DIVMS e os componentes químicos e anatômicos separadamente para cada espécie (Tabela 5). Nota-se a mesma tendência de resultados obtidos com o agrupamento das três espécies com as proporções de mesofilo e os teores de PB se correlacionando positivamente com a digestibilidade, enquanto todos os demais componentes químicos e anatômicos se correlacionaram negativamente. É interessante observar a variação dos resultados em decorrência da espécie. Assim, enquanto em lâminas foliares de capim-braquiária e capim-gordura praticamente todas as características anatômicas se correlacionaram significativamente com a DIVMS, em capim-tifton 85 apenas a espessura da parede de células do esclerênquima apresentou correlação significativa. Em colmos de capim-braquiária e capim-tifton 85, foram significativas e negativas as correlações da DIVMS com a proporção de esclerênquima, a espessura da parede de células do esclerênquima e os componentes da fração fibrosa e positivas com a proporção de parênquima e o teor de PB. Em capim-gordura, por outro lado, apenas o teor de PB se correlacionou positivamente e o de FDN e a espessura da parede celular no esclerênquima negativamente com a DIVMS. Das características anatômicas e químicas do colmo, melhores correlações com a DIVMS foram observadas para a proporção de esclerênquima e a espessura de suas paredes, e para os teores de PB e FDN, considerando as três espécies. Na fração lâmina, melhores correlações com a DIVMS das três espécies foram observadas para os teores de PB, FDN e FDA.

Entre os coeficientes de correlação da DIVMS com as características anatômicas e químicas obtidos com os dados agrupados das espécies (Tabela 4), $73 \%$ foram significativos, enquanto com os dados analisados para cada espécie (Tabela 5), de apenas $52 \%$. Além do maior número de observações, o agrupamento das espécies permitiu ampliação das diferen- 

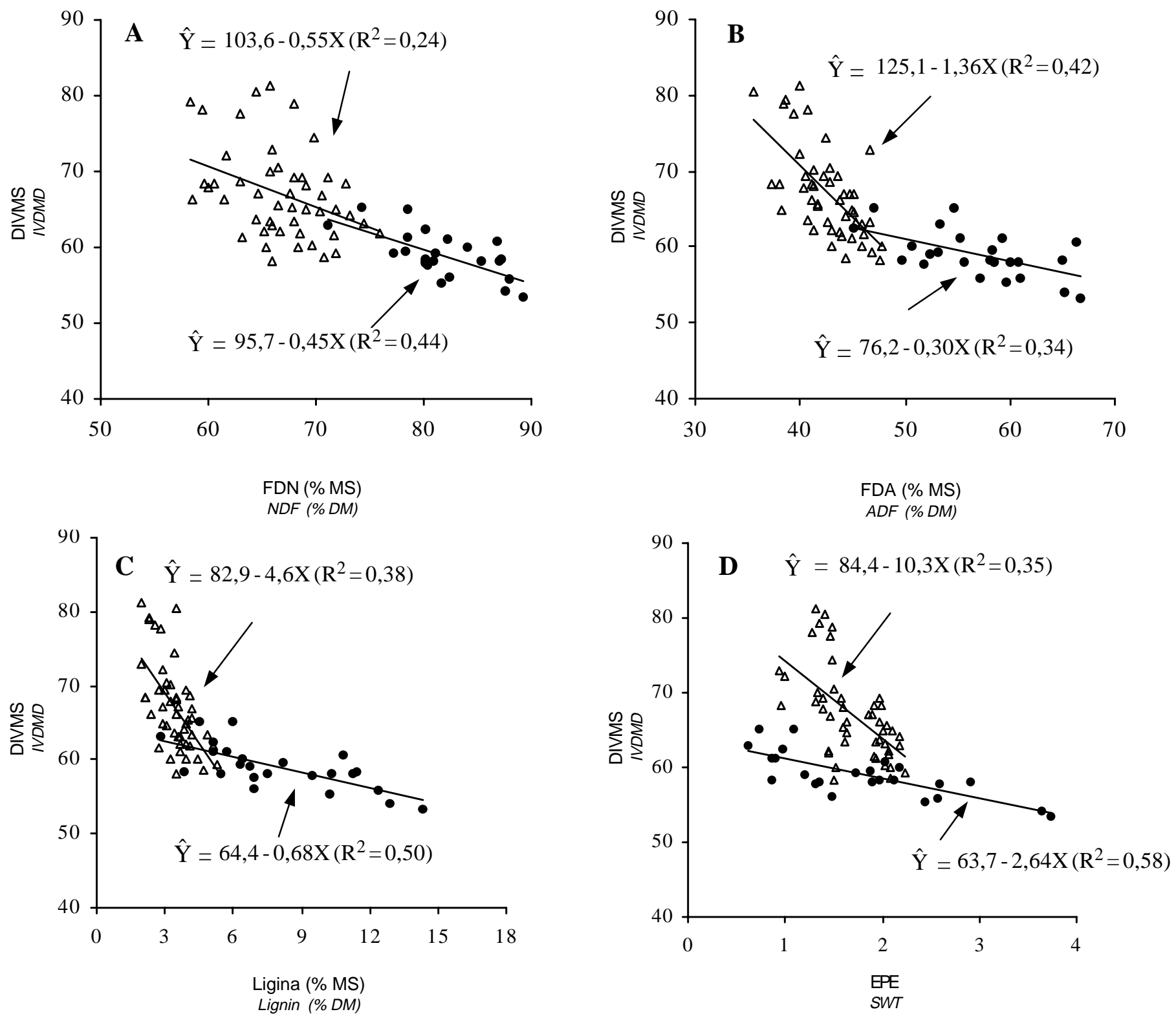

Figura 1 - DIVMS de lâminas foliares (- $\triangle-)$ e colmos (-1-), em função dos teores de (A) fibra em detergente neutro (FDN), (B) fibra em detergente ácido (FDA) e (C) lignina e (D) da espessura da parede de células do esclerênquima (EPE).

Figure 1 - IVDMD of leaf blades (- $\triangle-$ ) and stems (-1-), according to (A) neutral detergent fiber (NDF), (B) acid detergent fiber (ADF), and (C) lignin contents, and (D) sclerenchyma cell wall thickeness (SWT).

ças entre valores extremos dos componentes químicos e anatômicos e da DIVMS. A literatura revela, por exemplo, que fortes correlações negativas entre o teor de lignina e a DIVMS são consistentemente obtidas quando a avaliação inclui várias espécies de gramíneas (JUNG e ALLEN, 1995).

Em geral, melhores correlações da DIVMS foram obtidas com os componentes químicos. Com os dados da Tabela 5, é possível calcular maior número de correlações significativas da DIVMS com os componentes químicos que aquelas entre a DIVMS e os componentes anatômicos na lâmina foliar, no colmo e no agrupamento dos dados das duas frações. Também QUEIROZ (1997) concluiu que os componentes químicos de três gramíneas forrageiras propiciaram melhores correlações com a DIVMS que componentes anatômicos. Ainda assim, as elevadas correlações da DIVMS com a proporções de mesofilo e bainha parenquimática dos feixes $(\mathrm{P}<0,01)$ na lâmina foliar e de xilema e esclerênquima $(\mathrm{P}<0,001)$ no agrupamento de todas as espécies e frações e, principalmente, com a espessura da parede celular, inde- 
Tabela 5 - Correlações lineares entre a DIVMS e os componentes químicos e anatômicos de lâminas foliares e colmos de gramíneas forrageiras Table 5 - Linear correlations between IVDMD and chemical and anatomical components in leaf blades and stems of forages grasses

\begin{tabular}{|c|c|c|c|c|c|c|c|c|c|}
\hline \multirow[t]{2}{*}{$\begin{array}{l}\text { Variável }^{1} \\
\text { Variable }\end{array}$} & \multicolumn{3}{|c|}{$\begin{array}{l}\text { Lâmina foliar } \\
\text { Leafblade }\end{array}$} & \multicolumn{3}{|c|}{$\begin{array}{l}\text { Colmo } \\
\text { Stem }\end{array}$} & \multicolumn{3}{|c|}{$\begin{array}{c}\text { Lâmina foliar + colmo } \\
\text { Leaf blade + stem }\end{array}$} \\
\hline & $\begin{array}{c}\text { Capim- } \\
\text { braquiária } \\
\text { Signalgrass }\end{array}$ & $\begin{array}{c}\text { Capim- } \\
\text { gordura } \\
\text { Molassesgrass }\end{array}$ & $\begin{array}{c}\text { Capim- } \\
\text { tifton } 85 \\
\text { Tifton } 85 \\
\text { bermudagrass }\end{array}$ & $\begin{array}{c}\text { Capim- } \\
\text { braquiária } \\
\text { Signalgrass }\end{array}$ & $\begin{array}{c}\text { Capim- } \\
\text { gordura } \\
\text { Molassesgrass }\end{array}$ & $\begin{array}{c}\text { Capim- } \\
\text { tifton } 85 \\
\text { Tifton } 85 \\
\text { bermudagrass }\end{array}$ & $\begin{array}{c}\text { Capim- } \\
\text { braquiária } \\
\text { Signalgrass }\end{array}$ & $\begin{array}{c}\text { Capim- } \\
\text { gordura } \\
\text { Molassesgrass }\end{array}$ & $\begin{array}{c}\text { Capim- } \\
\text { tifton } 85 \\
\text { Tifton } 85 \\
\text { bermudagrass }\end{array}$ \\
\hline $\begin{array}{l}\text { Número de observações } \\
\text { Number of observations }\end{array}$ & 16 & 16 & 16 & 8 & 8 & 8 & 24 & 24 & 24 \\
\hline $\begin{array}{l}\operatorname{MES}(P A R) \\
\operatorname{BPF}(P B S)\end{array}$ & $\begin{array}{l}0,62 * * \\
-0,44 *\end{array}$ & $\begin{array}{l}0,61 * * \\
-0,42\end{array}$ & $\begin{array}{l}0,34 \\
0,06\end{array}$ & $\begin{array}{l}0,24 \\
-\end{array}$ & $\begin{array}{l}0,53 \\
-\end{array}$ & $\begin{array}{l}0,58 \\
-\end{array}$ & $-0,02$ & 0,01 & $0,51 * *$ \\
\hline $\mathrm{XIL}(X Y L)$ & $-0,65 * *$ & $-0,55^{*}$ & $-0,39$ & $-0,05$ & $-0,14$ & $-0,51$ & 0,23 & $-0,32$ & $-0,55 * *$ \\
\hline $\mathrm{ESC}(S C L)$ & $-0,44 *$ & $-0,43^{*}$ & $-0,41$ & $-0,77 * *$ & $-0,52$ & $-0,66^{*}$ & $-0,23$ & $-0,28$ & 0,07 \\
\hline $\operatorname{EPE}(W T S)$ & $-0,74 * * *$ & $-0,71 * *$ & $-0,55^{*}$ & $-0,84 * *$ & $-0,62 *$ & $-0,64 *$ & $-0,76 * * *$ & $-0,73 * * *$ & $-0,58 * *$ \\
\hline $\operatorname{EPM}(W T M)$ & $-0,68 * *$ & $-0,68 * *$ & $-0,42$ & $-0,57$ & $-0,43$ & 0,01 & $-0,54 * *$ & $-0,72 * * *$ & $-0,38 *$ \\
\hline $\mathrm{PB}(C P)$ & $0,76 * * *$ & $0,60 * *$ & $0,80 * * *$ & $0,88 * *$ & $0,65^{*}$ & $0,84 * *$ & $0,65 * * *$ & $0,71 * * *$ & $0,74 * * *$ \\
\hline $\mathrm{FDN}(N D F)$ & $-0,65 * *$ & $-0,58 * *$ & $-0,62 * *$ & $-0,89 * *$ & $-0,61^{*}$ & $-0,74^{*}$ & $-0,66 * * *$ & $-0,63 * * *$ & $-0,14$ \\
\hline $\operatorname{FDA}(A D F)$ & $-0,74 * * *$ & $-0,65 * *$ & $-0,57^{*}$ & $-0,88 * *$ & $-0,58$ & $-0,83 * *$ & $-0,58 * *$ & $-0,70 * * *$ & $-0,60 * *$ \\
\hline $\mathrm{LIG}$ & $-0,60 * *$ & $-0,35$ & $-0,78 * * *$ & $-0,87 * *$ & $-0,56$ & $-0,71 *$ & $-0,70 * * *$ & $-0,49 * *$ & $-0,69 * * *$ \\
\hline
\end{tabular}

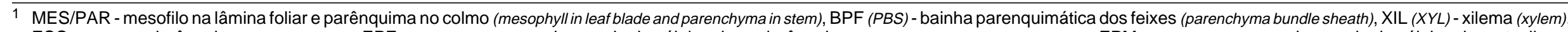
ESC (SCL) - esclerênquima (sclerenchyma), EPE (WTS) - espessura da parede de células do esclerênquima (sclerenchyma cell wall thickness), EPM (WTM) - espessura da parede de células do metaxilema (metaxylem cell wall thickness), PB (CP) - proteína bruta (crude protein), FDN (NDF) - fibra em detergente neutro (neutral detergent fiber), FDA (ADF) - fibra em detergente ácido (acid detergent fiber) e LIG - lignina

* $\quad(\mathrm{P}<0,05),{ }^{* *}(\mathrm{P}<0,01),{ }^{* * *}(\mathrm{P}<0,001)$. 
Rev. bras. zootec.

pendente da fração ou da espécie, revelam o potencial de tais características anatômicas como indicadoras da digestibilidade.

Os resultados confirmam que os tecidos pobremente digestíveis, como o xilema e o esclerênquima, se associam positivamente com a fração fibrosa da forragem e negativamente com os teores protéicos e com a digestibilidade, principalmente quando se agruparam os dados da lâmina e do colmo. Evidentemente, características químicas e físicas da parede celular destes tecidos explicam tais resultados. A lignina tem sido reconhecida como o principal componente químico limitante da digestibilidade da forragem (JUNG e DEETZ, 1993), o que foi evidenciado neste trabalho. A baixa digestibilidade das forrageiras tropicais pode decorrer, ainda, de problemas físicos como a elevada espessura da parede celular, podendo ser fator primário para limitação da digestão da parede celular (WILSON e MERTENS, 1995). Este fato foi realçado neste estudo com a elevada associação negativa entre a espessura da parede celular e a digestibilidade.

\section{Conclusões}

A espessura da parede de células do esclerênquima e do metaxilema foi a característica anatômica que mais fortemente se correlacionou com os componentes químicos e com a digestibilidade da forragem.

Os componentes químicos proporcionaram correlações significativas com a DIVMS, independente da fração considerada.

Estimativas das proporções de mesofilo, xilema e esclerênquima, juntamente com avaliações da espessura da parede celular, podem ser combinadas com a composição química para melhorar a estimativa de valor nutritivo.

\section{Referências Bibliográficas}

ABRAMS, S.M. 1988. Sources of error in predicting digestible dry matter from the acid-detergent fiber content of forages. Anim. Feed Sci. Technol., 21:205-208.

AKIN, D.E., CHESSON, A. Lignification as the major factor limiting forage feeding value specially in warm conditions. In: INTERNATIONAL GRASSLAND CONGRESS, 16., 1989. Nice, France. Proceedings... Nice, 1989. p.1753-1760.

ASSOCIATION OF OFICIAL AGRICULTURAL CHEMIST AOAC. 1970. Official methods of analyses. Washintong, D.C.: AOAC. $1015 \mathrm{p}$.

HALIM, R.A., BUXTON, D.R., HATTENDORF, M.J. et al. 1989. Water-stress effects on alfalfa forage quality after adjustment for maturity differences. Agron. J., 81:189-194.

JUNG, H.G., ALLEN, M.S. 1995. Characteristics of plant cell wall affecting intake and digestibility of forages by ruminants. J. Anim. Sci., 73:2774-2790.

JUNG, H.G., CASLER, M.D. 1991. Relationship of lignin and esterified phenolics to fermentation of smooth bromegrass fibre. Anim. Feed Sci. Technol., 32:63-68.
JUNG, H.G., DEETZ, D.A. 1993. Cell wall lignification and degradability. In: JUNG, H.G., BUXTON, D.R., HATIFIELD, R.D. et al. (Eds.) Forage cell wall structure and digestibility. Madison: America Society of Agronomy, Crop Sci. Society of America, Soil Sci. Society of America. p.315-46.

JUNG, H.G., VOGEL, K.P. 1992. Lignification of switchgrass (Panicum virgatum) and big bluestem (Andropogon gerardii Vitman) plant parts during maturation and its effect on fibre degradability. J. Sci. Food Agric., 59:769-776.

JUNG, H.G., MERTENS, D.R., PAYNE, A.J. 1997. Correlation of acid detergent lignin and klason lignin with digestibility of forage dry matter and neutral detergent fiber. J. Dairy Sci., 80:1622-1628.

JUNG, H.G., SMITH, R.R., ENDRES, C.S. 1994. Cell wall composition and degradability of stem tissue from lucerne divergently selected for lignin and in vitro dry matter disappearance. Grass Forage Sci., 49:295-299.

LAETSCH, W.M. 1974. The C4 syndrome: a structural analysis. Annu. Rev. Plant Physiol., 25:27-52.

MINSON, D.J. 1982. Effect of chemical composition on feed digestibility and metabolizable energy. Nutr. Abstr. Rev., 52:592-614.

NELSON, C.J., MOSER, L.E. 1994. Plant factors affecting forage quality. In: FAHEY, G.C. (Ed.) Forage quality, evaluation, and utilization. Madison: America Society of Agronomy, Crop Sci. Society of America, Soil Sci. Society of America. p.115-54.

QUEIROZ, D.S. 1997. Características anatômicas, químicas e digestibilidade in vitro de três gramíneas forrageiras. Viçosa-MG: UFV, 1997.90p. Tese (Doutorado em Zootecnia) - Universidade Federal de Viçosa.

QUEIROZ, D.S., GOMIDE, J.A., MARIA, J. 2000a. Avaliação da folha e do colmo de topo e base de perfilhos de três gramíneas forrageiras. 1. Digestibilidade in vitro e composição química. Rev. Bras. Zootec., 29(1):53-60.

QUEIROZ, D.S., GOMIDE, J.A., MARIA, J. 2000b. Avaliação da folha e do colmo de topo e base de perfilhos de três gramíneas forrageiras. 2. Anatomia. Rev. Bras. Zootec., 29(1):61-68.

SILVA, D.J. 1990. Análise de alimentos: métodos químicos e biológicos, 2.ed. Viçosa, MG: UFV. 165p.

TILLEY, J.M., TERRY, R.A. 1963. A two stage techinique for the in vitro digestion of forages crops. J. Brit. Grassl. Soc., 18(2):104-111.

VAN SOEST, P.J. 1994. Nutritional ecology of the ruminant. 2.ed. Ithaca: Cornell University. 476p.

WEISS, W.P. 1994. Estimation of digestibility of forages by laboratory methots. In: FAHEY, G.C. (Ed.) Forage quality, evaluation, and utilization. Madison: America Society of Agronomy, Crop Sci. Society of America, Soil Sci. Society of America. p.644-681.

WILSON, J.R. 1994. Cell wall characterisitcs in relation to forage digestion by ruminants. J. Agric. Sci., 122(2):173-182.

WILSON, J.R., MERTENS, D.R. 1995. Cell wall accessibility and cell structure limitations to microbial digestion of forage. Crop Sci., 35(1):251-259.

WILSON, J.R., ANDERSON, K.L., HACKER, J.B. 1989. Dry matter digestibility in vitro of leaf and stem of buffel grass (Cenchrus ciliares) and related species and its relation to plant morphology and anatomy. Aust. J. Agric. Res., 40(2):281-291.

WILSON, J.R., BROWN, R.H., WINDHAM, W.R. 1983. Influence of leaf anatomy on dry matter digestibility of $\mathrm{C}_{3}$, $\mathrm{C}_{4}$, and $\mathrm{C}_{3} / \mathrm{C}_{4}$ intermediate types of Panicum species. Crop Sci., 23(1):141-146.

Recebido em: 22/12/00 Aceito em: 25/04/01 